\title{
ASO Author Reflections: Tumor Location Affects Local Recurrence in Rectal Cancer
}

\author{
Clemens Franz, MD' ${ }^{1}$, and Yakup Kulu, $\mathrm{MD}^{1}$ \\ Department of General, Visceral and Transplant Surgery, University Hospital Heidelberg, Heidelberg, Germany
}

\section{PAST}

The circumferential resection margin (CRM) is one of the most important prognostic indicators in rectal cancer. ${ }^{1}$ Preoperative magnetic resonance imaging and evaluation of the CRM can identify those patients at high risk for local recurrence. $^{2}$ Current guidelines recommend neoadjuvant treatment in all patients with American Joint Committee on Cancer (AJCC) stage II and III rectal cancer. However, local recurrence rates are similar with and without neoadjuvant treatment before surgery if only high-risk patients are selected for treatment. ${ }^{3,4}$

The importance of variable mesorectum thickness in local recurrence has not been investigated to date. We hypothesized that ventrally located tumors are more prone to local recurrence than dorsally located tumors because of the varying thickness of the mesorectum. To test this hypothesis, we retrospectively analyzed all patients who underwent radical rectal resection for mid- and low-rectal cancer in our department between October 2001 and December 2013.

ASO Author Reflections is a brief invited commentary on the article "Prognostic Impact of Ventral Versus Dorsal Tumor Location After Total Mesorectal Excision of Rectal Cancer", Ann Surg Oncol. Epub 23 Sep 2019. https://doi.org/10.1245/s10434-019-07842-6.

\section{(C) Society of Surgical Oncology 2019}

First Received: 15 October 2019;

Published Online: 31 October 2019

Y. Kulu, MD

e-mail: yakup.kulu@med.uni-heidelberg.de

\section{PRESENT}

Our results show that ventral tumor location is an independent risk factor for local recurrence. Tumor location also affected how much patients benefited from neoadjuvant therapy-irradiation reduced local recurrence rates in patients with ventrally located tumors, but not in patients with dorsally located tumors. ${ }^{5}$

\section{FUTURE}

Tumor location is easy to define during preoperative diagnostics. Therefore, based on our results, we propose that tumor location should be considered in future studies on rectal cancer.

DISCLOSURES Clemens Franz and Yakup Kulu report no conflicts of interest.

\section{REFERENCES}

1. Nagtegaal ID, Quirke P. What is the role for the circumferential margin in the modern treatment of rectal cancer? J Clin Oncol. 2008;26(2):303-312.

2. Taylor FG, Quirke P, Heald RJ, et al. Preoperative high-resolution magnetic resonance imaging can identify good prognosis stage I, II, and III rectal cancer best managed by surgery alone: a prospective, multicenter, European study. Ann Surg. 2011;253(4):711-719.

3. Ruppert R, Junginger T, Ptok H, et al. Oncological outcome after MRI-based selection for neoadjuvant chemoradiotherapy in the OCUM Rectal Cancer Trial. Br J Surg. 2018;105(11):1519-1529.

4. Kulu Y, Tarantino I, Billeter AT, et al. Comparative outcomes of neoadjuvant treatment prior to total mesorectal excision and total mesorectal excision alone in selected stage II/III low and mid rectal cancer. Ann Surg Oncol. 2016;23(1):106-113.

5. Franz C, Lang HM, Ghamarnejad O, et al. Prognostic impact of ventral versus dorsal tumor location after total mesorectal excision of rectal cancer. Ann Surg Oncol. Epub 23 Sep 2019. https://doi. org/10.1245/s10434-019-07842-6.

Publisher's Note Springer Nature remains neutral with regard to jurisdictional claims in published maps and institutional affiliations. 